work. The risk was greatest in metal foundries and heavy engineering.

In the matter of protection, it was disheartening to find so many goggles which steamed up, restricted vision, and were uncomfortable to wear. The issue" of goggles to every individual worker, each being given a choice of four designs, in a large engineering factory had demonstrated that a great decrease in accidents could be achieved.

Ocular injuries could often be repaired now that the complication of infection was largely absent; all the same, even a small scar in the centre of the cornea could cause disability by dazzle in artificial light. Eye protection should be compulsory in occupations involving striking and chipping with a metal tool. Burns from molten metal and chemicals, especially caustic soda, were dangerous. Immediate irrigation with water might be the means of saving the eye.

In his paper on "Eye Protection, Types of Equipment and their Use", Mr. G. V. Thom, Plastics Division Safety Officer, Imperial Chemical Industries Ltd., explained the legal obligations to provide protection for the eyes against certain hazards which are laid down by the Factories Acts and are required by Common Law.

Built-in protection upon the machine, rather than upon its operator, was desirable, and he showed illustrations of typical methods of applying this principle.

Personal eye protection included spectacles, which could have prescription lenses made in safety glass, eye shields covering a part or all of the face, and goggles. Protection against infra-red rays was needed in welding and against ultra-violet as well in electric arc welding, which necessitated screening the whole of the face. British Standards for protective appliances were in existence. Persons with monocular vision should be given special attention because of the risk of total blindness, particularly because the existence of their disability might be unsuspected at the works.

It was suggested in the discussion that old hammers and chisels with mushroomed heads were a common source of intraocular foreign bodies; the risk was decreased by regular replacement of worn tools. Limitation of the field of vision by goggles, especially downwards, and interference with binocular vision discouraged their use. Other points raised were the need for safety glass, plastics which were not inflammable, and the fact that coloured glass which gave protection against radiation from flame welding might be useless for arc welding.

Mr. H. Bradley, Director of the British Boot and Shoe and Allied Trades Research Association, spoke first on the protection of the feet and was followed by Mr. H. E. Thomas, Head of the Safety Department of the Ford Motor Company, Dagenham. Mr. Bradley outlined the steps which had led to the drafting of a British Standard for safety footwear. These have a steel toe-cap which has to resist an impact test. In the experience of $\mathrm{Mr}$. Thomas the standard safety boot or shoe did, in some instances, give protection, but there were still many cases of toe fracture while wearing them. He suggested that the metal toe box be extended further back, even though this meant it would be unable to pass the impact test.

\section{ORDINARY SCIENTIFIC MEETING}

An ordinary scientific meeting of the British Occupational Hygiene Society was held at the London School of Hygiene and Tropical Medicine on June 20. Dr. T. Bedford was in the chair and some 50 members were present. A brief summary of the papers contributed to this meeting is given below.

\section{Exposure to Trichloroethylene during an Industrial Degreasing Operation}

D. E. Hickish, J. H. Smith, and Joan Bedford reported the results of a routine examination of a typical degreasing operation using a toxic solvent. The methods of collection and subsequent analysis of air samples were discussed. Urine specimens and blood samples were examined and clinical examinations performed. Concentrations of the solvent in air in excess of those recommended as the maximum allowable were discovered. Some abnormalities in the blood and urine specimens and mild clinical symptoms were noted. There were, however, no major pathological disorders.

The need for routine supervision of potentially dangerous operations was emphasized.

\section{Procedures relating to the Safety and Hygiene of Persons Handling Tetraethyl Lead in the U.K. and Overseas}

P. R. Boyd outlined the tetraethyl lead hazard with reference to the areas and spheres of activity in which this compound is handled. The general administration and supervision of those exposed to the potential absorption of this material were discussed in relation both to the manufacturers and to the customers and users.

The detailed control in terms of plant hygiene and human monitoring was briefly described, showing the combined use of clinical supervision and of analysis of human excreta and of the atmospheric environment.

The tetraethyl lead industry is a good example of one involving severe occupational hazards which can be controlled by detailed supervision.

\section{A Small Outbreak of Mercurialism in Laboratory Workers}

J. F. Erskine described a small outbreak of mercury poisoning in laboratory workers analysing mine air samples. Symptoms were minimal but the probable cause was confirmed by the finding of mercury in the urine. The risk was partly eliminated by cleaning the laboratory and improving the working conditions. It was finally eliminated by a change in the method of analysis so that open vessels of mercury were no longer required.

The outbreak demonstrated the risk of chemical poisoning to laboratory workers when, by increasing demand, ordinary laboratory techniques are converted to mass production methods, and the fact that the risk can be eliminated by the normally accepted methods of plant hygiene. 


\section{Assessment of Silicotic Fibrosis by a Chemical Method}

B. D. Stacy said that the development of fibrosis in tissues could be studied qualitatively by histological procedures. For assessing the extent of fibrosis throughout an entire organ, e.g., lung or liver, these techniques are somewhat limited ; a more quantitative approach to the problem has been made by the application of chemical methods.

"Fibrosis" implies the formation of the fibrous proteins reticulin and collagen. A chemical method has been adapted for determining them, and a relation has been sought between total tissue collagen and the severity of the fibrosis. The chemical determination is based on the estimation of hydroxyproline, collagen being unique in containing a high proportion $(14 \%)$ of this amino-acid. By the use of standard chromatographic procedures the protein under investigation was also checked and studied in relation to its general amino-acid composition, to ensure that it was similar to collagens previously described in the literature.

The method has been applied to three series of animal experiments designed to study (1) the fibrogenic effect of different forms of free silica; (2) the fibrogenic effect of varying amounts of tridymite ; (3) the effect of cortisone on developing and established silicosis. In these experiments the collagen values, determined chemically, have strongly supported and quantitatively extended histological observations on the development of fibrosis.

\section{A Survey of Respiratory Symptoms and Pulmonary Disability in a Random Sample of the Population of an Industrial Town}

I. T. T. Higgins said that respiratory disability in coal-miners was usually due either to pneumoconiosis or to bronchitis. While the former is caused by exposure to dust at work, the latter is common in men who have never worked in dusty occupations. Before incriminating the occupation it must be shown that the prevalence of the disease is higher in miners than in the non-mining population from which they are recruited.

In November, 1954, the Pneumoconiosis Research Unit carried out a survey on a random sample of the male population aged 55 to 64 of Leigh, Lancashire. The main purpose was to compare the prevalence of respiratory symptoms and pulmonary disability found in miners with that found in non-mining controls.

The respiratory symptoms were recorded, using a questionnaire, and occupational histories were taken to enable the required grouping to be effected. The ventilatory capacity was assessed by a single breath method.

Chest radiographs revealed those men with pneumoconiosis and other significant pulmonary disease. It was found that miners and ex-miners had significantly more chronic bronchitis and a significantly lower ventilatory capacity than men who had never mined.

The prevalence of bronchitis was lower in miners whose radiographs showed pneumoconiosis than in those with normal radiographs. In contrast the ventilatory capacity was higher in the men with pneumoconiosis than in those without.

\section{Some Factors Affecting Absence Rates}

R. B. Buzzard said that absence rates were variously used as indices of health, morale, or efficiency in working groups, or as criteria for testing selection procedures, training methods, or work processes ; but controlling the many factors which affect them in order to examine one was extremely complex.

Assumptions about the meaning of absence rates need questioning. "Lost" time depends on the time people are asked or permitted to work ; increased attendance may accompany increased average lost time. Early researches of the Industrial Health Research Board showed the amount and nature of work to be among the causes of differences in attendance; little research has been done on the optimum attendance for different tasks. Apart from effects of direct fatigue, a man who is off colour may be fit to attend for light work but not for heavy physical tasks. Conventional absence rates may be markedly affected by the behaviour of a few people ; they do not necessarily reflect the behaviour of the group. Short absences contribute less to average rates than long ones but most people agree that they upset production more; lost production cannot be calculated from average lost time rates.

The study of absences is medically important but handicapped by ignorance of the attendance which should be expected for particular jobs in particular conditions. Systematic observation of men at work is needed as a complement to any study of lost time statistics. 